\title{
A Notable Exhibition of Physical Apparatus.
}

CHE Physical Society of London and the Optical Society held their twelfth exhibition of electrical, optical, and other apparatus at the Imperial College of Science on January 4 and 5. As in past years, the exhibition rooms were crowded with apparatus and visitors; the latter were so numerous that the exhibition became a continuous one instead of closing between 6 and 7 p.m. each day. The display of scientific apparatus was probably the finest ever seen in this country, and the quality and finish of the instruments left little to be desired. There were many instruments of novel design, but attention can be directed to a few only.

A quite novel exhibit was an optical sonometer by the firm of Hilger, Ltd. This is designed to record the pressure variations caused by sound-waves, and should prove invaluable to workers in acoustics. The most novel feature is the diaphragm; which is a film having a thickness of a fraction of a wave-length of light, and is silvered or gilded on one side by a cathode process. The sound-wave under examination is received by a horn, and causes the diaphragm, and ultimately a beam of light, to vibrate. An intense point image is produced, and a photographic record can be obtained on a rotating film. The vowel sounds and all kinds of acoustic disturbances may thus be analysed. In another arrangement, which is excellently adapted for demonstration purposes, a rotating band with white lines 'on a dark ground is illuminated by a line image from the diaphragm. By adjustment of the speed of rotation stationary wave effects are obtained.

The episcope, shown by Newton and Co., is a marked improvement on forms previously seen, and should come into more general use for the projection on screens of opaque objects. The present instrument is of beautiful design, and with its two 2000candle-power lamps very bright pictures of opaque objects may be projected on a screen 5 metres or more away. In large teaching institutions this instrument could be put to many uses.

The Marconi Co. exhibited its new automatic alarm which responds to the wireless call of a ship in distress. In the present form of instrument the distress call must consist of three dashes, each of four seconds' duration, the dashes being separated by one-second intervals. By means of an amplifying circuit, plungers working in dash-pots are caused to respond to the four-second impulses, and after a series of three such impulses a warning signal occurs. If the impulses last for more or less than four seconds, subject to a tolerance of about half a second, the circuit necessary to operate the alarm is not completed. The demonstrations given were accompanied by artificial atmospherics and continuous wireless reception, and were remarkably successful.

Creed and Co. again showed their system of highspeed automatic printing of wireless messages, but at an increased speed of reception. Signals from Chelmsford were regularly received, the Morse code perforations in a paper strip being transposed into Roman characters by an automatic printer. The speed ranges from 50 to 200 words per minute.
While the writer was present a message was received from the Marconi Co. conveying its wishes for the success of the exhibition. The receiving a arial appeared to be a very insignificant affair, and many visitors marvelled at the present efficiency of triodevalve amplifiers.

A novel weather foreteller, the design of which is due to Mr. Kitchen, was shown by Negretti and Zambra. The instrument is based on meteorological data extending over many years. The forecast for twelve hours appears in a small window in the instrument after the barometer and wind-scales have been set to correspond to the conditions existing at the time. It would be of interest to have a record over six months of "predictions" and "happenings."

Tucker's hot-wire resonator microphone was shown by $H$. W. Sullivan. The microphone consists of a heated wire in the neck of a resonator and is insensitive to all but the particular sound frequency which it is desired to receive. The hot wire is cooled by the oscillating air-currents at the resonant frequency, and the change in the resistance of the wire is caused to operate an amplifier.

The Cambridge and Paul Instrument Co. exhibited a novel temperature regulator, in which the current from a thermo-couple in a furnace passes through a millivoltmeter, at the end of the pointer of which is a light thermo-couple in series with a moving coil relay. When the furnace is at the temperature which it is desired to maintain, the light thermo-couple is brought, by the movement of the pointer, into close juxtaposition to a small heated body. A current is thus generated which operates the relay and indirectly controls the current in the furnace. The instrument exhibited controlled a small electric furnace at about $700^{\circ} \mathrm{C}$. within about $5^{\circ} \mathrm{C}$.

The Edison Swan Co. showed a ro,ooo-candlepower pointolite lamp of ingenious construction; many visitors remarked on the skill required to seal leads into glass for the passage of a current of $40 \mathrm{am}$ peres. The firm of Ilford, Ltd., showed a new and im. proved colourless filter which completely cuts off ultraviolet rays. It is claimed to be much superior to the usual æsculin filter, and is known as " $Q$ " (acetaminoquinoline). The Davison microtelescope, while not new, attracted considerable attention, and users of the microscope admired a new 25-watt mercury vapour lamp made by Chas. Baker. Shotter's integrator for water-flow meters was shown by $\mathrm{H}$. Tinsley; it represents a new application of the Wheatstone bridge. Among precise measuring instruments the Campbell fundamental standard of mutual inductance (shown by R. W. Paul) must be mentioned, and also the "Talymin," by Taylor, Taylor and Hobson, which determines within small limits of error the outside diameters of small manufactured parts.

An experimental lecture on "The Johnsen-Rahbek Electrostatic Telephone and its Predecessors" was given on both days by. Mr. A. A. Campbell Swinton. Another lecture on "Radium: Its Application in Peace and War" was delivered bv Mr. F. Harrison Glew, and a third lecture on "The Employment of Coarse Wire Gratings in Astronomy" was given by Sir Frank W. Dyson. These lectures were attended by large audiences, and were highly appreciated.

\section{Science in Secondary Schools}

THE twenty-second annual general meeting of the Science Masters' Association, which was held last week at the Imperial College of Science, was presided over by the Master of Balliol. His address on the subject of the relationship of history and NO. 2724 , VOL. IO9] science will long be remembered by those who were fortunate enough to hear it for the genial humour and literary grace with which he defined the position and importance of these complementary branches of learning. 
The association has been growing steadily in size and influence, and in recent years more than one important development in scientific education has taken its origin in the deliberations of its assemblies. Unless we are mistaken, we may expect to see, as a result of this meeting, a serious endeavour to introduce the fundamental principles of physical chemistry in the early stages of science teaching. Brig.-Gen. $H$. Hartley made this suggestion both in the interests of intellectual economy and of clear thinking. It was time, he said, that they tried to simplify for their pupils the memorising of the ever-growing mass of known chemical facts by showing them at the outset how these are co-ordinated; thus would pure memory work be reduced, being replaced by reasoning which was well within the powers of the students. Prof. J. C. Philip, who, in common with other speakers, strongly supported this view, emphasised the importance of introducing the physico-chemical ideas into the ordinary chemistry courses in preference to teaching physical chemistry as a separate subject at the start. It was further explained that neither expensive apparatus nor extraordinary mathematical ability on the part of the pupils is necessary in the early stages of such instruction. It is rare to find in a big gathering such unanimity of opinion that a change of this sort in traditional teaching is both desirable and possible. In all probability more will be heard of it.

During the course of the meetings, which extended over two days, there were several other discussions, of which the following general impressions were obtained:-First, as regards the teaching of dynamics; this is still, with rare exceptions, in a chaotic condition in our schools. The subject is often left in the hands of mathematical masters, and divorced from the teaching of science. In any case, the presentation of mechanics is usually far too formal, with the result that it makes little appeal to beginners.

Geography seems to be in a better way. Some attempt was made at the meeting to define, perhaps to limit, the activities of the specialist teacher of geography. But it was fairly generally agreed that he had made good, and that science has much to gain and nothing to lose by the growing importance which is being attached to the modern geographer's methods.

Major E. R. Thomas, in opening a discussion on post-certificate science for the non-specialist, spoke of the importance of emphasising the cultural value of the subject. For this class of student especially it is desirable to bring into prominence the historical, biographical, and philosophical aspects of the subject. This kind of teaching is now being widely adopted, and is already being reflected in the work of those who are specialising in science. For many years the association has done its utmost to save the youth of the country from the materialistic tendencies which may follow from the study of natural science if it is narrowly conceived and inadequately expounded.

The discussions will be fully reported in the next issue of the School Science Review, which Mr.
G. H. J. Adlam will continue to edit. During the coming year Sir Ernest Rutherford will be the president of the association, of which Major V. S. Bryant (St. Piran's School, Maidenhead) and Major C. E. Sladden (Eton College) are the secretaries.

The annual meeting of the Association of Science Teachers was held at University College, London, on January 3 last. At a business meeting in the morning the following resolution was unanimously passed:"That this meeting of the Association of Science Teachers deeply regrets the action of the University of Cambridge, in that, alone among British universities, it continues to exclude women from membership. The association believes that such exclusion must be prejudicial to the higher education of women in general, and especially in natural science, for the study of which Cambridge can offer exceptional advantages."

A very useful discussion on practical examinations in science, initiated by a resolution concerning general elementary science as a subject in the General School Examination of the University of London, was made more valuable by the presence of $\mathrm{Mr}$. Lea, representing the University. The general sense of the meeting was in favour of the retention, or even extension, of practical tests in science as a part of the First Examination.

In the afternoon Dr. Winifred Brenchley, of the Rothamsted Experimental Station, lectured on "Tht Effects of Competition on Plant-life." She pointed out that competition is prevalent both above and below ground. In the soil the deficiency of any constituent of plant-food may become a limiting factor in the growth of the plant, and the elements which act most frequently in this way are nitrogen and phosphorus, and to a less extent potassium. Tests on this point are made by pot-cultures, in which the composition of the soil can be controlled. By such tests it can be shown that with scanty nourishment one plant will increase as much in dry weight as a number of plants crowded into the same amount of soil.

Above ground the limiting factor is light, leaf mosaics and other leaf arrangements being an adaptation to this condition. The effect of light is not always obvious, as crowded plants are taller than "spaced" ones, but a comparison of dry weights shows that the "spaced" plant increases 50 per cent. more than the crowded one.

Plants are adapted to live in communities on a limited amount of soil by varying root depth, e.g. during the drought of last summer bird's foot trefoil flourished exceedingly because it had deep roots. Cultivated plants cannot exist at all in competition with weeds. Investigations undertaken at Rothamsted have shown the extraordinary vitality of weedseeds, and work is now proceeding on a survey of weeds of various districts. In this matter Dr. Brenchley seeks to enlist the help of schools in various parts of the country, and will be glad to send details as to the data required to anyone who can help in this way.

\section{Problems of Animal Breeding.}

A $\mathrm{N}$ interesting series of articles on research in animal breeding appeared in the April-July issues of the Journal of the Ministry of Agriculture. In the first two papers the author, Prof. R. C. Punnett, traces the results of crossing red with black and polled with horned cattle, and in this way illustrates the Mendelian principles underlying all.breeding methods. Mendelism not only enables the breeder to understand why red calves sometimes NO. 2724 , VOL. IO9] appear even in the most highly pedigreed Aberdeen, Angus, or Holstein cattle, but it also supplies the knowledge which can be used to prevent their ever appearing again. The factors with which breeders are concerned are rarely as simple as in the blackred case of cattle, where the possibilities form a simple alternative pair, and in both cases one of the characters is completely dominant to the other, black being dominant to red and polled to horned. A more 